\title{
A Critical Review of Measures of Innovativeness
}

\section{Ms. Jessica Menold}

Jessica Menold is a doctoral student in mechanical engineering at the Pennsylvania State University. As an undergraduate at Penn State she was heavily involved with a STEM outreach program called the engineering ambassadors. She currently works as a graduate mentor for entrepreneurial student groups on campus as a part of Penn State's Lion Launch Pad team. Her interests in entrepreneurs, as well as engineering education, has led her to the study of innovation in engineers, working with Dr. Kathryn Jablokow. Her current research focuses on understanding innovation in engineering professionals and students, and she is collaborating with a team at Purdue to create a tool to measure innovativeness among engineers.

\section{Dr. Kathryn Jablokow, Pennsylvania State University}

Dr. Kathryn Jablokow is an Associate Professor of Mechanical Engineering and Engineering Design at Penn State University. A graduate of Ohio State University (Ph.D., Electrical Engineering), Dr. Jablokow's teaching and research interests include problem solving, invention, and creativity in science and engineering, as well as robotics and computational dynamics. In addition to her membership in ASEE, she is a Senior Member of IEEE and a Fellow of ASME. Dr. Jablokow is the architect of a unique 4-course module focused on creativity and problem solving leadership and is currently developing a new methodology for cognition-based design. She is one of three instructors for Penn State's Massive Open Online Course (MOOC) on Creativity, Innovation, and Change, and she is the founding director of the Problem Solving Research Group, whose 50+ collaborating members include faculty and students from several universities, as well as industrial representatives, military leaders, and corporate consultants.

\section{Dr. Senay Purzer, Purdue University, West Lafayette}

Şenay Purzer an Assistant Professor in the School of Engineering Education and is the Director of Assessment Research for the Institute for P-12 Engineering Research and Learning (INSPIRE) at Purdue University. In 2011, she received a NSF CAREER award, which examines how engineering students approach innovation. She is also a NAE/CASEE New Faculty Fellow. She is an editorial board member for the Journal of Pre-College Engineering Education (JPEER) and the journal of Science Education. Purzer conducts research on the assessment of difficult and often vaguely defined constructs such as innovativeness, information literacy, engineering design, and data-driven decision-making. Purzer has M.A. and Ph.D. degrees in Science Education from Arizona State University. She also has a B.S. degree in Physics Education and a B.S.E. in Engineering.

\section{Dr. Daniel Michael Ferguson, Purdue University, West Lafayette}

Daniel M. Ferguson is the recipient of three NSF awards for research in engineering education and a research associate at Purdue University. Prior to coming to Purdue he was Assistant Professor of Entrepreneurship at Ohio Northern University. Before assuming that position he was Associate Director of the Inter-professional Studies Program and Senior Lecturer at Illinois Institute of Technology and involved in research in service learning, assessment processes and interventions aimed at improving learning objective attainment. Prior to his University assignments he was the Founder and CEO of The EDI Group, Ltd. and The EDI Group Canada, Ltd, independent professional services companies specializing in B2B electronic commerce and electronic data interchange. The EDI Group companies conducted syndicated market research, offered educational seminars and conferences and published The Journal of Electronic Commerce. He was also a Vice President at the First National Bank of Chicago, where he founded and managed the bank's market leading professional Cash Management Consulting Group, initiated the bank's non credit service product management organization and profit center profitability programs and was instrumental in the breakthrough EDI/EFT payment system implemented by General Motors. Dr. Ferguson is a graduate of Notre Dame, Stanford and Purdue Universities and a member of Tau Beta Pi. 


\section{Dr. Matthew W. Ohland, Purdue University and Central Queensland University}

Matthew W. Ohland is Professor of Engineering Education at Purdue University and a Professorial Research Fellow at Central Queensland University. He has degrees from Swarthmore College, Rensselaer Polytechnic Institute, and the University of Florida. His research on the longitudinal study of engineering students, team assignment, peer evaluation, and active and collaborative teaching methods has been supported by over $\$ 12.8$ million from the National Science Foundation and the Sloan Foundation and his team received Best Paper awards from the Journal of Engineering Education in 2008 and 2011 and from the IEEE Transactions on Education in 2011. Dr. Ohland is past Chair of ASEE's Educational Research and Methods division and a member the Board of Governors of the IEEE Education Society. He was the 2002-2006 President of Tau Beta Pi. 


\title{
A Critical Review of Measures of Innovativeness
}

\begin{abstract}
Understanding, evaluating, and promoting individual innovativeness is a critical step in cultivating engineering leaders for the future. As a means of evaluating the gaps in current research related to innovativeness assessment, this paper analyzes ten measures and models of innovativeness through two lenses: (1) their internal vs. external point of reference (i.e., attribute vs. action); and (2) their relationship to key elements of cognitive function (i.e., cognitive level, style, and affect). From this review, it is clear that a comprehensive, rigorously validated psychometric instrument does not yet exist to assess the aptitudes, skills, knowledge, personal traits, and behaviors that are indicative of an innovative engineer. This work highlights the potential for such an instrument to help transform engineering education by enhancing student insights about innovation across programs.
\end{abstract}

\section{Introduction}

With the constant drive for innovation in our economy and the increasing demand to graduate students who are more innovative contributors to society, it is little wonder that interest in defining and measuring individual innovativeness is growing. Attempts date back to the 1970s, with some scholars focusing on a general definition and assessment of innovativeness, while domain-specific work has tended to focus on consumer behavior. Somewhat surprising is the fact that efforts to define and measure engineering innovativeness as a construct have been few and far between. Our long-term research agenda aims to rectify this situation through an extended project focused on identifying and assessing the key factors of engineering innovativeness ${ }^{1}$. Specifically, our work involves the development of a socially constructed definition of engineering innovativeness, the validation of an instrument (or suite of instruments) to measure engineering innovativeness, and the creation of a benchmark database of engineering innovativeness among engineering students and practitioners.

To support our efforts, we conducted an initial critical review of existing instruments designed to assess innovative characteristics and/or behaviors in individuals, considering both general innovativeness and engineering innovativeness in particular. As examples, assessments of general innovativeness include the 20-item Innovation subscale (JI) of the Jackson Personality Inventory $^{2}$, Hurt et al.'s Innovativeness Scale (IS) ${ }^{3}$, and Kirton's Adaption-Innovation Inventory (KAI) ${ }^{4}$. For measuring engineering innovativeness, Fisher et al.'s study of mental models about the personal attributes, skills, processes, and environments required for innovation is enlightening ${ }^{5}$, along with Ragusa's Engineering Creativity and Propensity for Innovation Index (EPCII) ${ }^{6}$, which is based on ten theoretical constructs that have been partially validated in a pilot study. Our critical review of these and other measures of innovativeness includes an analysis of their internal/external point of reference (attribute vs. action) and the cognitive element(s) they address (level, style, or affect). We close our review with recommendations for the development of new assessments for innovativeness, comments on the limitations of our study, and plans for future work in this domain. 


\subsection{Framework for Critical Review}

Each innovation measure or model in our review was evaluated through two lenses: (1) internal vs. external point of reference (i.e., do the constructs/factors attempt to assess a human attribute or a human action); and (2) key elements of cognitive function ${ }^{4,7}$ (i.e., are the constructs/factors examples of cognitive level, cognitive style, or cognitive affect). These lenses enabled us to review each of the measures/models consistently and to evaluate them based on their relevance, usability, and application to our own research agenda.

\subsection{Lens \#1: Attribute vs. Action}

Innovativeness can be measured from both internal and external perspectives, i.e., considering an individual's internal characteristics ("who they are") or an individual's external actions ("what they do"). Thus, our first lens for evaluation will consider whether each construct or factor of an innovativeness measure or model is focused on assessing some internal attribute of an individual or an external action that relates to and/or supports innovativeness. As examples, internal attributes include personality traits and other cognitive characteristics of an individual, such as intelligence, knowledge, skills, and motivation. An individual's natural strengths and weaknesses are dependent on these personal attributes. Actions are defined as the behaviors or habits of an individual that - in this case - lead to innovative output, whether or not they are characteristic of the individual. Both attributes and actions may relate to elements of cognitive function.

\subsection{Lens \#2: Cognitive Function}

As defined by Kirton ${ }^{4,7}$, an individual's cognitive function (i.e., thinking function), is composed of three elements or functional "departments": cognitive affect, cognitive effect, and cognitive resource. Cognitive affect serves as a filter that helps us choose which problems we will solve and the solutions to those problems that we find acceptable. Cognitive affect is driven by a person's needs, values, attitudes, and beliefs - i.e., the motivation behind one's behavior. For example, an individual's "moral compass" helps dictate which activities he/she will engage in and which he/she will avoid, including the problems that individual chooses to address and the solutions he/she chooses to pursue.

Cognitive effect is the "planning department" of cognitive function that plans and implements the solutions to problems, from conceptual beginning to detailed conclusion. Cognitive effect is influenced by the innate individual characteristics of cognitive style and potential level, both of which are stable over time. Cognitive style (sometimes called preferred style or problem solving style) is typically defined in terms of consistent individual differences in a person's preferred ways of organizing and processing information and experience ${ }^{4}$. Examples of cognitive style include the Sensing-Intuition dimension of Jung's psychological types and Kirton's AdaptionInnovation continuum, which reflects an individual's preference for structure ${ }^{4,7}$. Research shows that cognitive style is unchanged across a person's lifetime, but coping behavior can be used when needed (at an increased cognitive cost) to behave in ways that do not align with a person's cognitive style ${ }^{4,7}$ - i.e., while style is fixed, behavior is flexible. Next, potential level describes an individual's innate capacity for acquiring particular types of knowledge or skills - i.e., the size of the "mental bucket" that individual has available. Examples of potential level include intelligence, aptitude, and talent - all of which can be assessed in many different ways. 
Finally, cognitive resource (also known as manifest level) is the brain's storehouse of skills and knowledge; it is the collection of everything an individual learns and retains ${ }^{4}$. Examples of cognitive resource/manifest level include the knowledge gained from on-the-job experiences, all forms of education, learned skills, and expertise. Unlike potential level, which is stable, cognitive resource/manifest level is constantly changing, accumulating across one's entire lifespan. Cognitive resource serves the demands of cognitive affect and effect, supplying them with information as they perform their filtering, planning, and implementing functions. In general, when measuring potential level, manifest level, and cognitive style, we expect normal distributions over large, general populations.

\section{Search Context and Scope}

Our critical review focused on two main areas of innovation assessment research: general measures of innovativeness, and models and measures of engineering innovativeness. Entrepreneurial orientation was also reviewed briefly, but it is largely outside the scope of this early review and will be pursued in more depth at a later date. The current review was conducted to analyze the state of psychometric instruments devoted explicitly to innovativeness (in part or as a whole). In total, 22 articles were reviewed; 10 of these articles contained models or measures of innovativeness that were analyzed in depth, while the remaining 12 articles served as background for our review. Through these articles, five measures of general innovativeness, three models of engineering innovativeness, and two measures of engineering innovativeness were analyzed and evaluated; these will be discussed in more depth in the next section.

\section{Measure and Model Evaluations}

\subsection{General Innovativeness}

Soutar described innovativeness as a general personality trait that can be defined as a predisposition to accept an innovation ${ }^{9}$. This definition helps make two important distinctions: first, that general innovativeness is related to personality, and second, that it is centered on the acceptance of "new" things. The first distinction can be applied to all of the works considered in this review of general innovativeness instruments. The second distinction helps distinguish two major areas of study in general innovativeness, namely: consumer behavior and personality research. Innovativeness studies in consumer behavior (i.e., consumer innovativeness) focus on identifying traits that specifically aid consumers in the adoption of new products and processes, while innovativeness studies in personality research tend to evaluate individual innovativeness in terms of innate traits and characteristics (which apply to more than new product adoption).

We will discuss these two major areas of study in general innovativeness research in the following sub-sections. First, under measures of consumer innovativeness, we will review two measures: the Innovation Scale of Hurt et al. ${ }^{3}$ and the Use Innovativeness instrument of Price and Ridgeway $^{10}$. Next, under measures of innovativeness as personality, we will review two measures and one model: the Adaption-Innovation Inventory of Kirton ${ }^{4}$, Jackson's Personality Scale $^{2}$, and Hunter et al.'s model of innovativeness ${ }^{11}$. 


\subsubsection{Measures of Consumer Innovativeness}

Steenkamp et al. ${ }^{12}$ defined innovativeness as a predisposition to buy new and different products and brands, rather than remain with previous choices and consumer patterns. Other consumerrelated research defines innovativeness as a propensity to adopt new ideas and techniques earlier than one's peers ${ }^{13}$ or the degree to which an individual is receptive to new ideas ${ }^{14}$. Studying consumer innovativeness has fascinated scholars for some time, and it is actively researched in marketing and business today. Many of the psychometric measures developed in this domain define levels of innovativeness based on Rogers's diffusion of innovation model ${ }^{3,15}$, which attempts to explain how and at what rates innovations are accepted by consumers. This model separates consumers into five categories, namely: innovator, early adopter, early majority, late majority, and laggard - where the rate of adoption decreases from innovator to laggard.

\section{Hurt et al.'s Innovativeness Scale}

Some consumer innovativeness measures have used Rogers's model as the basis for their own instrument. For example, Hurt et al. ${ }^{3}$ based their 20-item inventory on the five categories of the innovation adoption process described above. Specifically, Hurt et al. defined innovativeness as a normally distributed underlying personality construct, which they interpreted as willingness to change $^{3}$. The authors created the Innovativeness Scale, which scores users on a continuum from 20 to 140 , where a score of 20 represents the lowest level of innovativeness, and a score of 140 represents the highest level ${ }^{16}$.

Each item of Hurt et al.'s instrument can be mapped to Rogers's five diffusion of innovation categories. In addition, all 20 items can be categorized as measuring cognitive style (as a personal attribute). For example, one item is focused on personal value for tradition, while another focuses on curiosity and risk taking ${ }^{3}$. All of the items in this scale measure willingness to change, unlike many other instruments, which measure multiple facets of innovativeness. In terms of our two lenses of analysis, Hurt et al.’s Innovativeness Scale is clearly focused on attributes of individuals, and specifically, on cognitive style.

\section{The Price-Ridgeway Scale}

Similarly, the Price-Ridgeway Scale ${ }^{10}$ also measures consumer innovativeness, but it is specifically concerned with product use. Innovation is defined as the combination of five traits: creativity and curiosity, voluntary simplicity, risk preferences, creative re-use, and multiple use of a product. After an initial factor analysis, creative re-use was combined with voluntary simplicity to create a four-factor scale. It is worth noting that all of the factors are defined in terms of use innovativeness, which refers to product adaptation created by consumers ${ }^{10}$.

Voluntary simplicity is defined as a preference for recycling older products for re-use; the items assessing voluntary simplicity are concerned with motivation for re-use and relate to cognitive affect. Creativity/curiosity is defined as creating new products or disassembling products to view their inner workings; the items measuring this factor relate to preferences that are indicative of cognitive style. Similarly, risk preference measures an aspect of cognitive style - i.e., the amount of risk with which an individual is comfortable. The items associated with these three factors assess human characteristics that underlie general, stable patterns of behaviors and so, are considered attributes. 
Finally, multiple use potential is defined as the relationship between a product's perceived value by an individual and the potential of the product to be used in multiple ways. The items for this factor measure action from a cognitive affect standpoint, however, multiple use potential of a product is not directly relevant to individual measures of innovativeness. In terms of our two lenses of analysis, then, the Price-Ridgeway Scale is primarily focused on attributes of innovativeness, with two of its factors related to elements of cognitive style, and one of its factors related to cognitive affect; the fourth factor is not directly relevant to our work.

In summary, Hurt et al. ${ }^{3}$ and Price and Ridgeway ${ }^{10}$ provide groundwork for the development of psychometric measures related to innovativeness. Although their research is primarily concerned with consumer innovativeness, a domain somewhat removed from engineering, their validated instruments measure certain aspects of innovativeness effectively. In particular, their assessment of the innate traits and characteristics of individuals will inform our own development of an instrument to assess engineering innovativeness in the next phase of our research.

\subsubsection{Measures of Innovativeness as Personality}

Personality research studies the overarching characteristics of individuals that not only dictate their adoption of products but determine their preferred thinking and problem solving approaches in general. Innovativeness and innovation are defined more broadly in this research; for example, Goldsmith discussed innovation as the introduction and application of processes, products, or procedures new to the relevant unit of adoption (individual, group, organization, or wider society) and intended to benefit that unit ${ }^{16}$. Kirton described innovativeness in terms of a general continuum of cognitive style that ranges from a preference for "doing things better" (more adaptive) to a preference for "doing things differently" (more innovative) ${ }^{4}$. Jackson, as part of his Innovation subscale, described an innovator as a creative and inventive individual who is capable of original thought, motivated to develop novel solutions to problems, who values new ideas and likes to improvise. ${ }^{2}$ The common thread in all these definitions/models and their associated measures is the consideration of the individual as a whole, as opposed to the description of a few traits that lead to a domain-specific behavior, as found in measures of consumer innovativeness. The remainder of this section will evaluate two measures and one model of innovativeness from the personality literature, namely: Kirton's Adaption-Innovation Inventory (KAI) ${ }^{4}$, Jackson's Innovation and Risk-Taking subscales ${ }^{2}$, and Hunter's work in innovativeness from a human resources perspective ${ }^{11}$.

\section{Kirton's Adaption-Innovation Inventory (KAI)}

First, Kirton's Adaption-Innovation Inventory (KAI) is a psychometric instrument that measures cognitive style (as one's style of problem solving) on a bipolar spectrum between two extremes: those who prefer the greatest amount of structure in problem solving (highly adaptive) to those who prefer the least amount of structure (highly innovative) ${ }^{4}$. The KAI measures an individual's cognitive style exclusively; it is based on the concept that more adaptive individuals prefer to solve problems in an evolutionary manner (working within boundaries and paradigms), while more innovative individuals prefer to solve problems in revolutionary ways (breaking boundaries and paradigms). The KAI is a 32-item, self-report inventory with three sub-factors: sufficiencyproliferation of originality, efficiency, and rule/group conformity - each of which measures a different aspect of cognitive style as an innate human attribute. 
Sufficiency-proliferation of originality refers to preferences manifested in idea generation: more adaptive individuals prefer to offer fewer ideas that are sound, useful and relevant, while more innovative individuals prefer to offer a multitude of ideas that are less dependent on current paradigms and organizational precedents. The second sub-factor, efficiency, is related to the systems and methods used in problem solving; the more adaptive tend to be more thorough and meticulous, while the more innovative tend to be more cross-cutting and less detailed. Finally, rule/group conformity relates to the ways in which individuals manage the structure of impersonal systems (rules) and personal systems (groups); the more adaptive prefer to solve problems by leveraging the rules, while innovators tend to disregard rules. In terms of our two lenses of analysis, the KAI is clearly focused on one attribute - cognitive style.

\section{The Jackson Personality Index}

Unlike KAI, the Jackson Personality Index ${ }^{2}$ does not place users on a continuum, but categorizes them into low and high scorers. Two subscales within the index are relevant to our current work: Innovation and Risk Taking. Although we could not gain direct access to the instrument, and so, could not evaluate each item in depth, we were able to find descriptions of Jackson's high and low scorers for both the Innovation and Risk Taking subscales, as follows:

- High Scorer Innovativeness: “A creative and inventive individual; capable of originality of thought; motivated to develop novel solutions to problems; values new ideas, likes to improvise." 17

- Low Scorer Innovativeness: "Has little creative motivation; seldom seeks originality; conservative thinker; prefers routine activities." ${ }^{17}$

- High Scorer Risk-Taking: "Enjoys gambling and taking a chance; willingly exposes self to situations with uncertain outcomes; enjoys adventures having an element of peril; takes chances unconcerned with danger." ${ }^{\prime 7}$

- Low Scorer Risk-Taking: "Cautious about unpredictable situations; unlikely to bet; avoids situations of personal risk, even those with great rewards; does not take chances regardless of whether the risks are physical, social, monetary or ethical." ${ }^{, 17}$

Like Kirton's KAI, the Jackson Personality Index ${ }^{2}$ as a whole is a measure of attributes, or innate personality characteristics. All four descriptions shown above focus mainly on the cognitive style construct (preference for structure), although there appears to be some confounding with cognitive level (i.e., implying that one type of thinking is "better" than another). There are also some slight indicators of cognitive affect (motivation) in these descriptions. Still, cognitive style seems to be the dominant element of cognitive function here, and so innovativeness and risk taking are categorized as attributes related to cognitive style.

\section{Hunter, et al.'s Model of Innovativeness}

Hunter et al. ${ }^{11}$ analyzed individual personality traits from a unique human resources perspective based on the organizational standpoint of hiring innovative individuals to increase a company's overall innovativeness. Unlike Kirton and Jackson, however, Hunter described innovativeness in terms of innovative output and stated that creative potential is a necessary but not sufficient prerequisite for it. Hunter et al. detailed the knowledge, skills, abilities (KSA's) and other characteristics that may be predictive of creative performance; however, the authors did not 
develop an instrument for measuring these KSA's ${ }^{11}$. Appendix A provides a diagram of Hunter's conceptual model; it depicts the inputs and outputs of creative potential, as well as touching on the external factors of innovative output.

The constructs of Hunter's model measure different aspects of cognitive function and provide a more complete view of an individual's innovative make-up. Domain specific expertise, broad knowledge base, and domain specific skills are all measures of manifest level, as they are dependent on an individual's education and experiential learning (e.g., gained on the job). Creative processing skills are indicative of an individual's preferred problem solving approach, and so are categorized as cognitive style, while intelligence is a direct measure of potential level. Divergent thinking, associational ability, and analogical ability are all categorized as cognitive style, as they describe the characteristic ways in which individuals prefer to process information. Dispositions and motivation are categorized as cognitive affect, because they describe the internal values and drivers of an individual. Only the first three of these ten constructs are descriptive of actions related to innovativeness; the rest relate to human attributes. In other words, Hunter's model focuses primarily on attributes of innovativeness, with three constructs related to manifest level (domain specific expertise, broad knowledge base, domain specific skills), four constructs related to cognitive style (creative processing skills, divergent thinking, associational ability, analogical ability) one related to potential level (intelligence), and two related to cognitive affect (dispositions, motivation).

In summary, both of the general innovativeness instruments discussed above (Kirton and Jackson) measure internal attributes over external actions, and while Hunter's model takes a broad view, he did not provide a measurement instrument. While valuable, these general measures of innovativeness are insufficient for the assessment of engineering innovativeness, because they fail to assess key non-innate traits (e.g., learned behaviors), skills, and abilities in engineering. Engineering innovativeness models and measures also need to map the specific traits and behaviors of innovative engineers onto the innovation process itself. The following section will review the few measures of engineering innovativeness we found in the literature.

\subsection{Engineering Innovativeness}

Work that focuses specifically on engineering innovativeness is fairly new, and as such, there are only a few measures and models that aim to assess directly the skills, traits, and behaviors necessary to be an innovative engineer. Much of the research to date is based on semi-structured interviews with experts in engineering innovation. The data from these interviews are used to construct models of ideal innovative characteristics, including both the innate traits of engineering innovativeness and corresponding skills and behaviors. The benefit of such engineering models and measures is that by providing feedback to engineering students and practitioners on both their innate traits and learned knowledge/skills, you can inform them about the innovative skills they can improve upon, as well as characteristic traits that cannot be changed. In the latter case, individuals can then learn coping techniques - i.e., techniques for behaving outside of one's innate preferences ${ }^{4}$ - to help them expand their range of behaviors in the academic and professional worlds. 
The following sections will review some of the models of engineering innovativeness, as well as the few existing measures. First, we will review three models of engineering innovativeness: the Innovator's DNA ${ }^{18}$, Fisher's mental models of innovation ${ }^{5}$, and Scott's determinants of innovative behavior ${ }^{19}$. Next, under measures of engineering innovativeness, we will review two measures: Ragusa's Engineering Creativity and Propensity for Innovation Index (ECPII) ${ }^{6}$, and Keller's work in predicting innovative performance in engineering professionals ${ }^{20}$.

\subsubsection{Models of Engineering Innovativeness}

\section{The Innovator's DNA Model}

The Innovator's DNA Model of Dyer et al. ${ }^{18}$ was validated and co-created through semistructured interviews with top leaders in innovation. Although this model does not address engineering innovativeness exclusively, it was validated and tested on 6000 business professionals, many of whom were engineers. The main findings of this research were five socalled "skills" necessary for innovative behavior, namely: associating, questioning, observing, experimenting, and networking - which the authors argued are learned (i.e., represent cognitive level). Based on their definitions, it seems more accurate to say that several of these "skills" are actually cognitive preferences (i.e., cognitive style constructs) rather than manifestations of cognitive level.

In particular, Dyers, et al., defined associating as connecting unrelated ideas in novel ways, which resembles Kirton's description of a more innovative cognitive style ${ }^{4}$. Likewise, questioning refers to being curious or continuously asking provocative questions, while experimentation relates to a certain level of risk-taking and engaging in new ideas in order to innovate new products, all of which resemble descriptors of cognitive style as well. In contrast, observing (observing phenomena in order to gain insights into potential markets or opportunities) and networking (continuously expanding one's network in order to gain new perspectives and insights) are both defined as actions that must be learned, making them closer to manifest cognitive level. In terms of our two lenses of analysis, then, the Innovator's DNA Model is focused on both attributes of and actions related to innovativeness, with three of its components (associating, questioning, experimentation) related to cognitive style, and two of its factors (observing and networking) related to manifest level.

\section{Fisher et al.'s Model of Innovativeness}

Fisher et al. conducted a pilot study of ten innovation experts to derive mental models of innovation ${ }^{5}$. Data from the interviews were organized in four categories as shown in Figure 1, namely: personal attributes, skills, environment for innovation, and process for innovation. Unlike other innovation models (e.g., the work of Dyers et al. ${ }^{18}$ ), Fisher et al.'s model includes environment. From the interviews, the researchers identified a list of innovation promoters and inhibitors that fall under each category. The promoters and inhibitors listed under personal attributes (e.g., preference for risk; curiosity; confidence) are associated with cognitive style. The skills category includes the domain-specific skills and knowledge necessary for innovative success, which are attributes corresponding to manifest level. Process for innovation is also related to manifest level (processes are examples of experiential knowledge that is learned), but this process is presented as an action more than an attribute. Finally, environment for innovation is described in terms that resemble the characteristic traits of Kirton's rule/group conformity sub- 
factor $^{4}$, and so is classified as cognitive style (as an attribute). In terms of our two lenses of analysis, then, Fisher et al.'s model of innovativeness is focused on both attributes of and actions related to innovativeness, with two of its factors related to elements of cognitive style (personal attributes, environment), and two of its factors related to manifest level (skills, process).

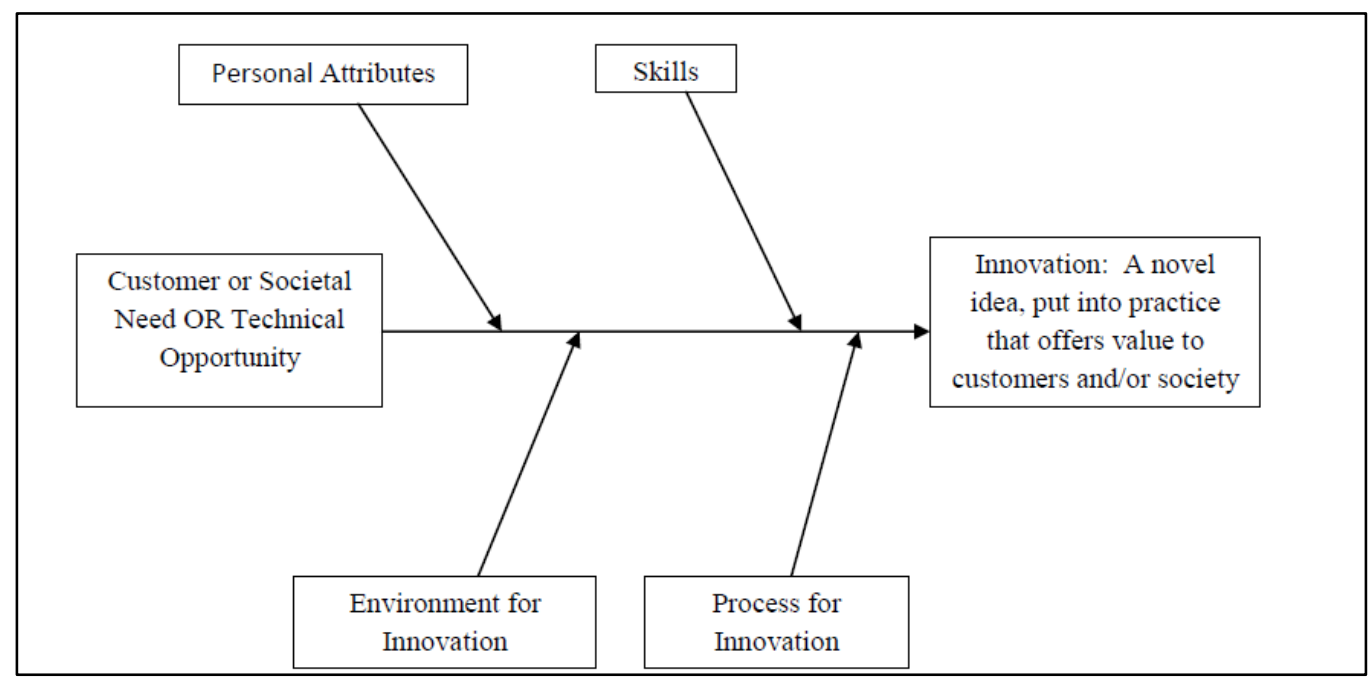

Figure 1. Fishbone Diagram of Innovation (Fisher et al. ${ }^{5}$ )

\section{Scott et al.'s Model of Innovative Behavior}

In their work on the determinants of innovative behavior, Scott et al. ${ }^{19}$ proposed a model of individual innovative behavior, theorized to be the outcome of four interacting systems related to the individual, leader, work group, and climate. Unlike other models of engineering innovativeness, this model is specifically concerned with employee output and workplace innovativeness. The four constructs of the model are correspondingly: problem solving style, leader, work group, and climate for innovation. Climate for innovation represents the signals an individual receives that dictates their interpretation of organizational expectations for behavior and potential outcomes of that behavior. Leader is based on the relationship between bosses and subordinates, and work group refers to the effect that collaborative work environments can have on individual innovativeness.

Climate for innovation, leader, and work group are all reminiscent of Kirton's rule/group conformity sub-factor ${ }^{4}$; however, as they are defined by Scott et al. ${ }^{19}$, they cannot be categorized as cognitive style. Instead, they are more closely related to cognitive affect, as they relate to the values and goals of the organization that affect an individual's value set and internal motivation. The only construct of the model that is concerned with personal attributes is problem solving style, which, unlike Kirton, describes two types of problem solvers rather than a continuum ${ }^{4}$. In terms of our two lenses of analysis, then, Scott et al.'s ${ }^{19}$ model of innovative behavior is focused on both attributes of and actions related to innovativeness, with one of its factors related to elements of cognitive style (problem solving style), and three of its factors related to cognitive affect (climate for innovation, leader, and work group). 
In summary, the models of engineering innovativeness discussed above provide a more complete view of the traits, skills, behaviors, and environmental factors that specifically affect engineering innovativeness when compared with general measures of innovativeness. Unfortunately, these models do not provide (or recommend) psychometric instruments to assess the constructs they describe. As such, engineering students and professionals must engage in a guessing game in order to evaluate their own innovative skills, traits, and behaviors. The following section will review the few available measures of engineering innovativeness we found in the literature.

\subsubsection{Measures of Engineering Innovativeness}

Psychometric measures of personality traits, behaviors, and skills directly related to engineering innovativeness are relatively few and far between, and as such, this critical review evaluates only two measures in this category. Unlike the models of engineering innovativeness discussed above, these two measures - i.e., Ragusa's Engineering Creativity and Propensity for Innovation Index (ECPII) ${ }^{6}$, which evaluates a tendency toward innovative thinking, and Keller's work, which attempts to predict the performance and innovativeness of scientists and engineers using existing instruments ${ }^{20}$ - were both based on previous work in psychological assessment rather than expert interviews. An important difference between the two measures is the target audience. Specifically, Ragusa's work centered on engineering students and a tool to measure innovativeness skills in undergraduates, while Keller's work evaluated the performance of engineering professionals and was concerned with predicting innovative output.

\section{Ragusa's Engineering Creativity and Propensity for Innovation Index (ECPII) ${ }^{6}$}

Ragusa's ECPII is designed to evaluate the relationship between engineering creativity and innovative behavior by taking stock of ten constructs of engineering innovativeness: engineering self-confidence, engineering self-strength, engineering artistry, engineering intellectuality, engineering flexibility, engineering fluency, engineering environmental sensitivity, disciplined imagination, engineering initiative, and engineering inquisitiveness. The definitions of these ten constructs can be found in Appendix B, where each construct is measured with three to six items (within a 40-item inventory) utilizing a four-point Likert scale ${ }^{6}$. Engineering self-confidence, flexibility, disciplined imagination, and inquisitiveness can be identified as individual attributes related to cognitive style. Engineering self-strength and initiative can be categorized as cognitive affect, because they are indicators of an individual's value system, as well as internal motivational drivers. Engineering artistry, fluency, and environmental sensitivity are related to manifest level, as they are dependent on one's engineering education and/or experiential knowledge. Engineering intellectuality is categorized as potential level, as it describes a student's "engineering IQ".

Of the ten constructs, only two are concerned with actions related to innovativeness - i.e., engineering initiative and engineering self-strength; interestingly, both are described as behavior rather than traits. Ragusa's instrument does an excellent job of addressing domain-specific skills and abilities that separate engineering innovativeness from general innovativeness. Unfortunately, however, full validation of the instrument has not yet been completed (to our knowledge). In terms of our two lenses of analysis, then, Ragusa's ECPII ${ }^{6}$ is clearly focused on attributes of innovativeness, with four of its factors related to elements of cognitive style, two related to cognitive affect, three related to manifest level, and one related to potential level. 


\section{Keller: Predicting the Performance of Engineers}

While Ragusa focused on engineering undergraduates in her research, Keller looked exclusively at engineering professionals. Unlike the general innovativeness measures and engineering innovativeness models discussed previously, Keller's work was concerned with determining the predictive characteristic traits that would lead to innovative output. Keller combined elements from four existing instruments to evaluate four personality traits: self-esteem, locus of control, need for clarity and an innovative orientation ${ }^{20}$. Self-esteem is described as one's perceived selfworth and was assessed using Rosenberg's 10 -item scale ${ }^{21}$; locus of control is the extent to which an individual believes they control factors of their life and was evaluated using Rotter's 23-item scale ${ }^{22}$; need for clarity is based on a person's ability to work in unclear situations and was evaluated using Ivancevich and Donnelly’s 6-item scale ${ }^{23}$; and innovative orientation is centered on problem solving and was evaluated using Kirton's 32-item $\mathrm{KAI}^{4}$.

Self-esteem can be categorized as an attribute and is descriptive of cognitive affect due to its relation to an individual's values and beliefs regarding self-awareness. Locus of control is also as an attribute of innovativeness and is related to cognitive style; it describes preferences of an individual for rule/group conformity ${ }^{4}$. Need for clarity is also identified as cognitive style, because it relates to an individual's preferences for structure; however, it is presented by Keller as an action, not an attribute. Finally, innovative orientation can be classified as an attribute and cognitive style; it is described (in the same manner as Kirton ${ }^{4}$ ) in terms of innate characteristics that separate different types of problem solvers. In terms of our two lenses of analysis, then, Keller's work is focused on attributes related to innovativeness, with three of its factors related to elements of cognitive style, and one of its factors related to cognitive affect.

\subsection{Summary of Our Findings}

Table 1 provides a summary of our findings based on the application of our two lenses of analysis to the measures and models of innovativeness we reviewed. In general, consumer measures of innovativeness assess attributes (as opposed to actions) and focus on cognitive style and affect. Both Kirton's and Jackson's general measures of innovativeness measure personal attributes (cognitive style) ${ }^{4,2}$, while Hunter's model of innovativeness provides a broader scope, highlighting attributes and actions, as well as a range of cognitive constructs (manifest level, potential level, cognitive style, and affect $)^{11}$. Similarly, the engineering measures and models focus mostly on personal attributes (with some actions) and the cognitive function components of cognitive style, manifest level, and affect ${ }^{5,18}$.

From these results, we conclude that a synthesis of engineering innovativeness models and measures, along with general measures of innovativeness, may lead to more robust and comprehensive psychometric instruments for the evaluation of innovativeness - both generally and for engineering in particular. Prior to discussing the implications of our results for engineering education, we will comment briefly on research in a parallel field - i.e., entrepreneurship. The study of entrepreneurial orientation has sometimes included innovativeness, and so some brief comments on this work seem appropriate here. 
Table 1. Summary of Our Findings

\begin{tabular}{|c|c|c|c|c|}
\hline Constructs & $\begin{array}{l}\text { Cognitive } \\
\text { Function }\end{array}$ & $\begin{array}{l}\text { Attribute or } \\
\text { Action }\end{array}$ & Authors & Classification \\
\hline Willingness to change & Cognitive Style & Attribute & Hurt et al. & Consumer \\
\hline Creativity and Curiosity & Cognitive Style & Attribute & \multirow{3}{*}{ Price, Ridgeway } & \multirow{3}{*}{ Consumer } \\
\hline Voluntary Simplicity & Affect & Attribute & & \\
\hline Risk Preferences & Cognitive Style & Attribute & & \\
\hline $\begin{array}{l}\text { Sufficiency-Proliferation of } \\
\text { Originality }\end{array}$ & Cognitive Style & Attribute & \multirow{3}{*}{ Kirton } & \multirow{3}{*}{ General } \\
\hline Efficiency & Cognitive Style & Attribute & & \\
\hline Rule/Group Conformity & Cognitive Style & Attribute & & \\
\hline Innovativeness & Cognitive Style & Attribute & \multirow{2}{*}{ Jackson } & \multirow{2}{*}{ General } \\
\hline Risk Taking & Cognitive Style & Attribute & & \\
\hline Domain Specific Expertise & Manifest Level & Action & \multirow{10}{*}{ Hunter et al. } & \multirow{10}{*}{ General } \\
\hline Broad Knowledge Base & Manifest Level & Action & & \\
\hline Domain Specific Skills & Manifest Level & Action & & \\
\hline Creative Processing Skills & Cognitive Style & Attribute & & \\
\hline Intelligence & Potential Level & Attribute & & \\
\hline Divergent Thinking & Cognitive Style & Attribute & & \\
\hline Associational Ability & Cognitive Style & Attribute & & \\
\hline Analogical Ability & Cognitive Style & Attribute & & \\
\hline Disposition & Affect & Attribute & & \\
\hline Motivation & Affect & Attribute & & \\
\hline Climate for Innovation & Affect & Action & \multirow{4}{*}{ Scott } & \multirow{4}{*}{$\begin{array}{l}\text { Engineering } \\
\text { Model }\end{array}$} \\
\hline Leader & Affect & Action & & \\
\hline Work Group & Affect & Action & & \\
\hline Problem Solving Style & Cognitive Style & Attribute & & \\
\hline Questioning & Cognitive Style & Attribute & \multirow{5}{*}{$\begin{array}{l}\text { Dyer, Gregersen, } \\
\text { Christensen }\end{array}$} & \multirow{5}{*}{$\begin{array}{l}\text { Engineering } \\
\text { Model }\end{array}$} \\
\hline Observing & Manifest Level & Action & & \\
\hline Networking & Manifest Level & Action & & \\
\hline Experimenting & Cognitive Style & Attribute & & \\
\hline Associational Thinking & Cognitive Style & Attribute & & \\
\hline Personal Attributes & Cognitive Style & Attribute & \multirow{4}{*}{ Fisher } & \multirow{4}{*}{$\begin{array}{l}\text { Engineering } \\
\text { Model }\end{array}$} \\
\hline Skills & Manifest Level & Attribute & & \\
\hline Process for Innovation & Manifest Level & Action & & \\
\hline Environment for Innovation & Cognitive Style & Attribute & & \\
\hline Engineering Self-Confidence & Cognitive Style & Attribute & \multirow{10}{*}{ Ragusa } & \multirow{10}{*}{$\begin{array}{l}\text { Engineering } \\
\text { Measure }\end{array}$} \\
\hline Engineering Self-Strength & Affect & Action & & \\
\hline Engineering Artistry & Manifest Level & Attribute & & \\
\hline Engineering Intellectuality & Potential Level & Attribute & & \\
\hline Engineering Flexibility & Cognitive Style & Attribute & & \\
\hline Engineering Fluency & Manifest Level & Attribute & & \\
\hline $\begin{array}{l}\text { Engineering Environmental } \\
\text { Sensitivity }\end{array}$ & Manifest Level & Attribute & & \\
\hline Disciplined Imagination & Cognitive Style & Attribute & & \\
\hline Engineering Initiative & Affect & Action & & \\
\hline Engineering Inquisitiveness & Cognitive Style & Attribute & & \\
\hline Self-Esteem & Affect & Attribute & \multirow{4}{*}{ Keller } & \multirow{4}{*}{$\begin{array}{l}\text { Engineering } \\
\text { Measure }\end{array}$} \\
\hline Locus of Control & Cognitive Style & Attribute & & \\
\hline Need for Clarity & Cognitive Style & Action & & \\
\hline Innovative Orientation & Cognitive Style & Attribute & & \\
\hline
\end{tabular}




\subsection{Measures of Entrepreneurial Orientation}

Entrepreneurial Orientation (EO) is frequently defined on an organizational level as a construct with three sub-dimensions: risk-taking, innovativeness, and pro-activeness ${ }^{24}$. Within this domain, Lumpkin and Dess ${ }^{25}$ defined the innovativeness of firms as a strong organizational commitment to support new ideas, novelty, experimentation, and creative processes that may result in new products, services or technological processes. Likewise, Acikdili et al. ${ }^{24}$ evaluated the effect of entrepreneurial orientation on new product development, and again, viewed entrepreneurial orientation and innovativeness as characteristics of a firm that reflect an organizational tendency to support new ideas. In both cases, innovativeness is identified as a component of EO that is seldom deconstructed any further than this loose association with the support of new ideas.

In other examples, Bolton et al. ${ }^{25}$ developed an instrument to measure individual entrepreneurial orientation by determining the personality traits and attitudes that positively affect EO. Of the entrepreneurship research reviewed here, this is the most closely related to our work. However, as with the firm-focused entrepreneurial orientation research discussed above, innovativeness is still treated as a sub-factor of a broader, overarching EO theme. Lau et al. ${ }^{27}$ also measured individual EO by evaluating entrepreneurial behaviors of corporate managers; specifically, ten entrepreneurial traits were identified through expert interviews, experience, and literature reviews. These ten traits were combined and reduced to four factors of entrepreneurial behavior: innovativeness, risk taking, change orientation, and opportunism, where Lau defined innovativeness as developing new or improved products or services. ${ }^{27}$

In general, entrepreneurial orientation research treats innovativeness as one sub-factor of a larger construct $^{24,25,26,27}$, while we are interested in the underlying factors and constructs of innovativeness itself. Thus, while entrepreneurial orientation research may be useful for benchmarking instrument development techniques, the main focus of EO research is not innovativeness per se, and so it will not be considered further in this critical review.

\section{Conclusions and Implications for Engineering Education}

Engineering students and graduates are challenged to adapt and solve problems in a fast-paced economy that demands creativity and innovativeness. In this context, engineering educators strive to develop and deliver curricula that enhance students' innovativeness in order to prepare them for successful careers in the future. Without a comprehensive means to evaluate and measure individual engineering innovativeness, however, both engineering educators and their students are left in the dark.

After evaluating the works identified in this review, it is clear that a robust and comprehensive psychometric instrument for the measurement of engineering innovativeness does not yet exist, although some progress has been made. Validated general measures of innovativeness do exist, but they fail to assess the domain-specific traits, skills, knowledge, and behaviors necessary for an engineer to be a successful innovator within the discipline ${ }^{3,2,4,16}$. Engineering models of innovativeness present traits, skills, and abilities of an engineering innovator based on analysis of expert interviews $5,18,19$, but these models fail to provide instruments to measure these characteristics. The few engineering innovativeness measures that do exist have not been 
validated extensively; they also vary in their definitions of innovativeness and in the output used to benchmark individual innovativeness ${ }^{6,20}$. Engineering education will be limited in scope and depth in terms of helping students realize their innovative potential until these gaps in knowledge and practice are bridged.

\section{Limitations of this Study and Future Work}

This critical review does not cover the entirety of innovativeness research, but for time and practicalities' sake, focuses on the topics most relevant to our current work. For example, although there may be informative results that fall under the umbrella of entrepreneurial orientation research, our team decided to review these works only briefly, as we were more concerned with the underlying facets of innovativeness in terms of engineering-specific definitions. We also limited the scope of this review to relevant work pertaining to the creation of a psychometric instrument that measures innovativeness in engineering students and professionals.

Future work will focus on the validation of a socially-constructed model of engineering innovativeness ${ }^{1}$ and the creation and validation of a psychometric instrument based on the skills, traits, and behaviors presented in that model. With a validated instrument in hand, we will benchmark both engineering students and practitioner populations in terms of their innovativeness profiles. The purpose of the above review was twofold: to highlight the need for this research and to lay the groundwork for a comprehensive psychometric instrument to evaluate engineering innovativeness.

\section{Acknowledgements}

This paper is based upon work supported by the National Science Foundation's Engineering Education Program under Grants \#1264769 and \#1264901. Any opinions, findings, conclusions, or recommendations expressed here are those of the authors and do not necessarily reflect the views of the National Science Foundation.

\section{References}

1. Purzer, S., Jablokow, K., Ferguson, D. M., Ohland, M. W., and J. Menold. (2014). “Collaborative research: Identifying and assessing key factors of engineering innovativeness,” Proc. of the 2014 ASEE Annual Conference \& Exposition (NSF Grantees Poster Session), Indianapolis, IN.

2. Jackson, D. N. (1976). Jackson personality inventory manual. Goshen, NY: Research Psychologists Press, Inc.

3. Hurt, H. T., Joseph, K., and C. D. Cook (1977). “Scales for the measurement of innovativeness,” Human Communication Research, 4(1): 58-65.

4. Kirton, M. J. (2011). Adaption-innovation: In the context of diversity and change. London: Routledge.

5. Fisher, E., Biviji, M., and I. Nair (2011). "New perspectives on teaching innovation to engineers: An exploration of mental models of innovation experts," Proc. of the 2011 ASEE Annual Conference \& Exposition, Vancouver, BC.

6. Ragusa, G. (2011). "Engineering creativity and propensity for innovative thinking in undergraduate and graduate students,” Proc. of the 2011 ASEE Annual Conference \& Exposition, Vancouver, BC. 
7. Kirton, M. J. (1976). “Adaptors and innovators: A description and measure,” Journal of Applied Psychology, 61(5): 622-629.

8. Messick, S. (1976). "Personality consistencies in cognition and creativity.” In S. Messick (Ed.), Individuality in learning. San Francisco: Jossey-Bass.

9. Soutar, G. N., and S. Ward (2008). "Looking at behavioral innovativeness: A Rasch analysis.” Journal of organizational and end user computing (JOEUC) 20(4): 1-22.

10. Price, L. L., and N. M. Ridgway (1983). "Development of a scale to measure use innovativeness.” Advances in consumer research 10(1): 679-684.

11. Hunter, S. T., L. Cushenbery, and T. Friedrich (2012). "Hiring an innovative workforce: A necessary yet uniquely challenging endeavor.” Human resource management review 22(4): 303-322.

12. Steenkamp, J.-B., and H. Baumgartner (1999). "A cross-national investigation into the individual and national cultural antecedents of consumer innovativeness.” Journal of marketing 63(2): 55-69.

13. Von Fleckenstein, F. (1974). “Are innovativeness scales useful?” Rural Sociology, 39(2): 257.

14. Midgley, D. F., and G. R. Dowling (1978). “Innovativeness: The concept and its measurement.” Journal of Consumer Research, 4:229-242.

15. Roehrich, G (2004). “Consumer innovativeness: concepts and measurements.” Journal of business research 57(6): 671-677.

16. Goldsmith, R. E. (1986). “Convergent validity of four innovativeness scales.” Educational and psychological measurement, 46: 81-87.

17. See Jackson (1976), p. 10.

18. Dyer, J. H., H. B. Gregersen, and C. M. Christensen (2009). “The innovator’s DNA.” Harvard business review 87(12): 61-67.

19. Scott, S. G., and R. A. Bruce (1994). "Determinants of innovative behavior: A path model of individual innovation in the workplace." Academy of management journal 37(3): 580-607.

20. Keller, R. T. (2012). "Predicting the performance and innovativeness of scientists and engineers.” Journal of Applied Psychology 97(1): 225.

21. Rosenberg, M. (1989). Society and the adolescent self-image. Wesleyan University Press.

22. Rotter, J. B. (1966). "Generalized expectancies for internal versus external control of reinforcement.” Psychological monographs: General and applied 80(1): 1.

23. Ivancevich, J. M., and J. H. Donnelly (1974). "A study of role clarity and need for clarity for three occupational groups.” Academy of management journal 17(1): 28-36.

24. Açıkdilli, G., and D. Y. Ayhan (2013). "Dynamic capabilities and entrepreneurial orientation in the new product development.” International journal of business and social science 4: 144-150.

25. Kreiser, P. M., and J. Davis (2010). "Entrepreneurial orientation and firm performance: The unique impact of innovativeness, pro-activeness, and risk-taking.” Journal of small business \& entrepreneurship 23(1): 39-51.

26. Bolton, D. L., and M. D. Lane (2012). "Individual entrepreneurial orientation: Development of a measurement instrument.” Education+ Training 54(2/3): 219-233.

27. Lau, T., et al. (2012). "The entrepreneurial behaviour inventory: A simulated incident method to assess corporate entrepreneurship.” International journal of entrepreneurial behaviour and research 18(6): 673-696. 
Appendix A: Hunter et al.’s Conceptual Model of Innovativeness ${ }^{11}$

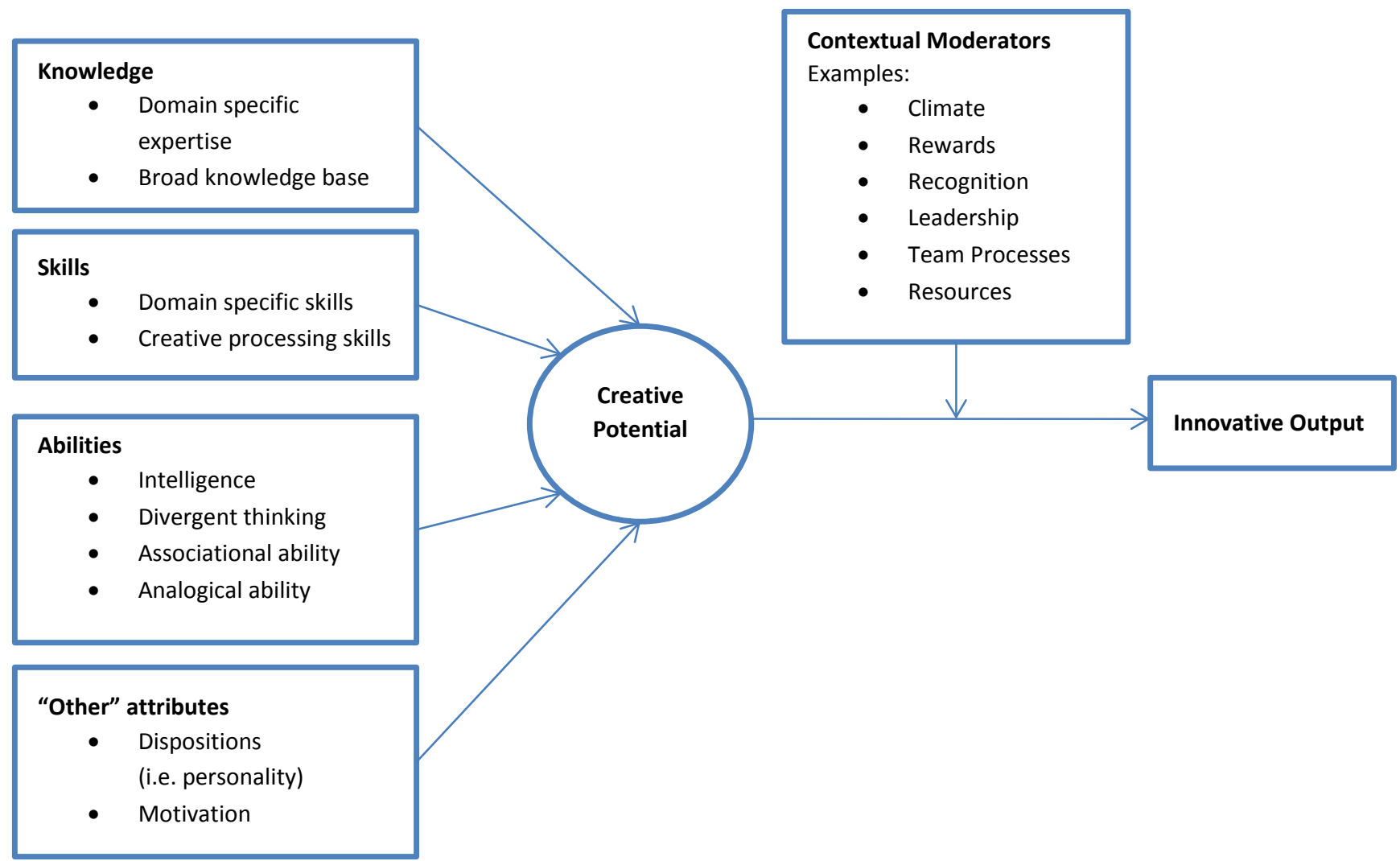


Appendix B: Definitions of Ragusa's Ten Constructs ${ }^{6}$

1. Engineering Self-Confidence: The degree to which the student exhibits self-confidence in his or her decisions

2. Engineering Self-Strength: The degree to which the student is able to operationalize his or her decisions in the face of adversity

3. Engineering Artistry: The student's ability to make sense and have fluency in engineering design

4. Engineering Intellectuality: Student's intellectual ability specific to the engineering domain

5. Engineering Flexibility: Degree of student's diversity in thinking processes within and beyond the engineering mindset in diverse engineering related settings

6. Engineering Fluency: Student's level and depth of understanding of diverse aspects of the engineering discipline

7. Engineering Environmental Sensitivity: Student's ability to recognize the importance of environment in his or her work

8. Disciplined Imagination: Student's ability to imagine diverse problem solving approaches within the engineering discipline, coupled with the ability to use a diverse engineering problem solving skill set in the face of distractors

9. Engineering Initiative: Student's ability to take action to work within the discipline without cuing or prompting

10. Engineering Inquisitiveness: Student's level and depth of curiosity about engineering processes, how things work, and diverse problem solving approaches within and beyond the discipline 